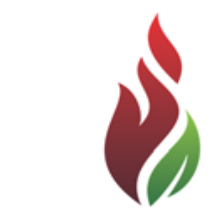

SUSTENERE

Publishing Corporation

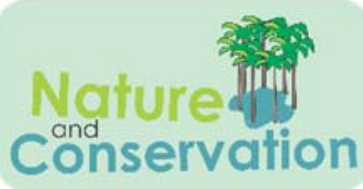

Journals Homepage:

www.sustenere.co/journals

\title{
A AGROECOLOGIA E OS SERVIÇOS AMBIENTAIS
}

\section{RESUMO}

Nos dias de hoje já é amplamente percebida a degradação dos serviços ambientais, dos solos e de outros recursos naturais promovidos pelo atual modelo de desenvolvimento agrícola. A agroecologia surge a partir desta constatação e nutre um modelo que seja capaz de realizar a produção agrícola e ao mesmo tempo, zelar pelos recursos naturais. Este trabalho propõe uma análise da relação entre o uso do solo para produção agrícola e os serviços ambientais, sob a ótica do modelo hegemônico de se produzir alimentos (sistema industrial - revolução verde) ou da agroecologia. A análise das externalidades promovidas pelos dois modelos deixa claro que os ganhos e vantagens que a agroecologia promove aos serviços ambientais e equilíbrio ecológico, e a coloca como um modelo que estabelece uma relação mais harmônica com a natureza, com preservação dos recursos naturais e serviços ambientais.

PALAVRA-CHAVE: Agroecologia; Economia Ecológica; Pagamentos por Serviços Ambientais; Externalidades.

\section{AGROECOLOGY AND ENVIRONMENTAL SERVICES}

\section{ABSTRACT}

Nowadays it is widely perceived degradation of ecosystem services, soil and other natural resources promoted by the current model of agricultural development. Agroecology emerges from this finding and nourishes a model that is able to carry out agricultural production and at the same time, look after the natural resources. This paper proposes an analysis of the relationship between land use for agricultural production and environmental services from the perspective of the hegemonic model to produce food (industrial system - green revolution) or agroecology. The analysis of externalities promoted by the two models makes it clear that the gains and advantages that agroecology promotes environmental services and ecological balance, and stands as a model establishing a more harmonious relationship with nature, with the preservation of natural resources and environmental services.

KEYWORDS: Agroecology; Ecological Economics; Payments for Environmental Services; Externalities.

Nature and Conservation, Aquidabã, v.7, n.1, Nov, Dez 2013, Jan, Fev, Mar, Abr, Mai, Jun, Jul, Ago, Set, Out 2014.

ISSN 2318-2881

\section{SECTION: Articles TOPIC: Ecologia}

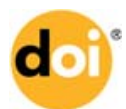

DOI: 10.6008/SPC2318-2881.2014.001.0002

Clovis José Fernandes Oliveira Júnior Instituto de Botânica, Brasil http://lattes.cnpq.br/1860421392471635 floraacao@gmail.com

Jennifer Leão dos Santos

Centro Universitário São Camilo, Brasil http://lattes.cnpq.br/2782942966991590 jenniferleao@yahoo.com.br

Helen Cristina Maximo

Centro Universitário São Camilo, Brasil http://lattes.cnpq.br/9058706810572088 hl maximo@yahoo.com.br

Received: 06/03/2014

Approved: 09/08/2014 Reviewed anonymously in the process of blind peer.

Referencing this:

OLIVEIRA JUNIOR, C. J. F.; SANTOS, J. L.; MAXIMO, H. C.. A agroecologia e os serviços ambientais. Nature and Conservation, Aquidabã, v. $7, n .1$, p.19-32, 2014. DOI: http://dx.doi.org/10.6008/SPC23182881.2014.001.0002 


\section{INTRODUÇÃO}

Alterações na cobertura da superfície terrestre e mudanças climáticas naturais são partes de um processo evolucionário que ocorrem naturalmente ao longo do tempo nos ciclos de vida do planeta terra (WORSTER, 2003). No entanto, a atividade agropecuária age como um catalisador destas mudanças e hoje é um dos principais agentes causadores de alterações significativas na crosta terrestre (ROMEIRO, 2003; 2011; VEIGA \& EHLERS, 2003). Na atualidade, pós-revoluções industrial e verde, as ações antrópicas se intensificaram e estão causando uma severa crise sobre a biodiversidade e os recursos naturais, com alterações significativas nas condições climáticas do planeta, um alto número de extinção de espécies e graves prejuízos aos serviços ambientais e funções ecológicas das quais a humanidade depende (ROMEIRO, 2003; BROOKS et al., 2006; CAPORAL et al., 2006; MORAN, 2008; MORAN \& OSTROM, 2009; ALTIERI, 2009).

A modernização agrícola, derivada da 'revolução verde', de fato aumentou a produtividade nas lavouras, mas seu objetivo produtivista, baseado na maximização de lucros, descartou as externalidades e levou a impactos ambientais indesejáveis. Deve-se considerar também que não atingiu o objetivo proposto de acabar com a fome no planeta. Os problemas ambientais mais frequentes, provocados pelo padrão produtivo monocultor foram: desestruturação dos solos e perda de sua fertilidade (EHLERS, 1996; LUTZENBERGER, 2001; VEIGA \& EHLERS, 2003), intensificação dos processos de erosão e assoreamento dos corpos d'água e chegando ao extremo em processos de desertificação, como no norte de Minas Gerais (VELEDA, 2011), ou no estado do Ceará (VIANA, 2010) entre outras áreas no Brasil. No Ceará as áreas em desertificação derivam, em grande parte, das áreas onde se plantava algodão antigamente. Como externalidades do processo produtivo se pode incluir ainda a destruição das florestas e da biodiversidade, com graves prejuízos aos processos de polinização e dispersão de sementes ou propágulos, além da contaminação dos recursos hídricos e dos alimentos pelo excessivo uso de agrotóxicos e adubos químicos (EHLERS, 1996; WORSTER, 2003; VEIGA \& EHLERS, 2003; BALSAN, 2006; ALTIERI, 2009).

Muitas destas alterações ocorridas estão descritas na Avaliação Ecossistêmica do Milênio (MA, 2005), podemos exemplificar: poluição e redução do nível da água nos lençóis freáticos, degradação dos ecossistemas, aumento do aporte desequilibrado de nutrientes (fósforo e nitrogênio entre outros) nos corpos d'água, causando desequilíbrio nas comunidades aquáticas; estas alterações têm mudado a dinâmica natural dos ecossistemas, modificando o estilo e a condição de vida, não só das espécies que fazem parte destes ecossistemas alterados, mas de todos os outros seres do planeta. Assim, a condição de vida atual de nosso planeta é o resultado da coevolução dos seres vivos com o ambiente no decorrer dos tempos. $E$ nas atividades humanas, especialmente na agricultura e pecuária, considerando a manutenção dos ciclos hidrológicos e a condição de solos saudáveis, Dal-Soglio (2009) nos alerta por estarmos destruindo as condições ecológicas necessárias a existência da vida. Não pensamos a agricultura 
como um processo de fluxo de energias, nem nos ciclos biogeoquímicos, sendo o modelo agrícola atual altamente dependente de energia e insumos externos, e em grande parte de derivados de petróleo (CAPORAL et al., 2006; SACHS, 2010). Em publicação de Dal-Soglio e Kubo (2009) é discutida a necessidade de repensarmos a agricultura como atividade 'promotora do desenvolvimento sustentável', na qual possamos efetivamente conciliar a produção agropecuária com a conservação dos recursos naturais em agro ecossistemas estáveis e resilientes.

Os estudos da ecologia política agrária nos mostram as transformações nas formas de uso e ocupação dos solos, e também o crescimento e desenvolvimento das atividades agropecuárias como um todo. Uma das principais transformações se deu a partir das descobertas de Justus Von Liebig, que trouxe o entendimento do papel dos nutrientes do solo e sua importância no crescimento das plantas, dando origem a adubação química. No entanto, foi o próprio Liebig também um dos primeiros críticos ao processo de "industrialização" da agricultura e seus nefastos efeitos que já pronunciavam (NASCIMENTO, 2009).

Os fluxos de energia e matéria que entram e saem dos sistemas, segundo os princípios da entropia na termodinâmica, geram ciclos caracterizados por transformações, partindo de sistemas simples para os mais complexos, nos quais a energia fica armazenada (GÖTSCH, 1995). O grande aporte de insumos externos cria enormes desequilíbrios energéticos que caracterizam a insustentabilidade ecológica dos sistemas de agricultura industrial (CAPORAL et al., 2006; ROMEIRO, 2011). Então, sendo de grande importância, os ciclos biogeoquímicos e os ciclos de energia proporcionam o equilíbrio dinâmico dos ecossistemas, formando a base de sua sustentabilidade e que geram recursos como água, solos, oxigênio, $\mathrm{CO}_{2}$, biodiversidade, ciclagem de nutrientes, alimentos, entre outros. Atuam diretamente na produção de água para abastecimento urbano e rural e mantém o fluxo gênico da flora e fauna, também proporcionam ao ser humano valores tais como espiritualidade, educação, recreação e beleza cênica (FOREST TRENDS, 2008; FASIABEN, 2009). Muito embora termos como externalidades e consequências ambientais indesejáveis na agricultura possam parecer temas recentes, no final do século XIX, os cientistas russos Vernadsky e Podolinsky já apresentavam ideias do que deveria ser uma visão ecológica e sistêmica do território, incluindo análise do fluxo de energia, eles foram pioneiros na proposição de análises visando um equilíbrio maior entre o homem e o planeta (NASCIMENTO, 2009).

Mundialmente, a importância dos serviços ambientais é percebida já na década de 60 , o livro 'Primavera silenciosa' de Rachel Carson, publicado em 1962, alertou a sociedade sobre as graves consequências do uso indiscriminado de produtos químicos na agricultura, na época o DDT (Dicloro-Difenil-Tricloroetano) era considerado a solução dos problemas com "pragas" nos campos e seu uso era amplo e indiscriminado, chegando ao absurdo de pulverizar nas pessoas para se evitar mosquitos, atualmente seu uso é proibido praticamente no mundo todo. Este livro de Carson tornou-se um clássico na luta ambientalista. 
O pensamento ambientalista ganhou novas dimensões com a Conferência de Estocolmo em 1972, na qual o Sociólogo francês Ignacy Sachs, entre outros, apresentou o termo 'ecodesenvolvimento', o qual, mais tarde, em meados da década de 1980, seria transformado em "desenvolvimento sustentável", com a construção e publicação do Relatório Brundland. A partir de então, o ativismo pelas questões socioambientais propagou-se por todo o planeta, pois tinha ficado evidente a influência das alterações do meio ambiente na qualidade de vida, e então a sociedade começou a compreender a necessidade de conservar os recursos naturais para as gerações futuras. Na década de 90, o desenvolvimento sustentável tornou-se objetivo da sociedade que buscava, segundo Romeiro (2003), uma alocação eficiente de fatores de produção, que pudesse contribuir para reverter à injusta concentração de renda e também proporcionar processos ecológicos mais equilibrados. Como visto, a agricultura convencional, de caráter industrial, da maneira como é planejada e praticada, tem colocado em risco o equilíbrio ambiental no planeta, embora esteja intrinsecamente ligada aos interesses de todos os povos da terra, pois se trata da produção de alimentos. Mas, infelizmente, nos últimos tempos têm também promovido acúmulo de poder, através da concentração de renda e terra, considerando também formas subumanas de exploração do trabalhador rural (PACíFICO, 2009).

Devido a má e intensa utilização dos recursos e dos ecossistemas naturais, ocasionando perturbações em sua resiliência, os serviços ambientais foram, então, sendo degradados, com prejuízos para toda humanidade. Devido não ter considerado as externalidades e suas consequências, a economia neoclássica foi cedendo espaço para a economia ambiental, procurando novas formas e ferramentas que pudessem contribuir para minimizar os desequilíbrios já amplamente percebidos. Uma das ferramentas introduzidas é a valoração, sendo o pagamento por serviços ambientais, um instrumento utilizado como forma de incentivo financeiro, através da inserção de preço monetário aos serviços ambientais (NOGUEIRA et al., 2000; GUEDES \& SEEHUSEN, 2011).

\section{DISCURSÃO TEÓRICA}

\section{Serviços Ambientais}

Para Sachs (2010), os camponeses são capazes de promover ações para que os serviços ambientais essenciais sejam valorizados e preservados. Evidentemente, será preciso incentivá-los e até remunerá-los por essas funções, começando por garantir aos camponeses, o acesso à terra e aos recursos naturais necessários para viverem. Caso contrário, além da perda dos serviços ambientais, será incitado o êxodo rural, ocasionando inchaço e superpopulação nas áreas periféricas e favelas dos grandes centros urbanos. Os serviços ambientais são produzidos pelos ecossistemas e utilizados pelos seres humanos para sua sobrevivência e bem-estar. A água, por exemplo, é um serviço utilizado para abastecimento humano, agricultura, dessedentação animal, 
indústria, entre outros. Todavia o uso deste recurso é determinado e limitado de acordo com o potencial de reposição hídrica dos corpos d'água locais, o que depende da conservação do solo e da cobertura vegetal, os quais são responsáveis pela capacidade de infiltração, armazenamento e disponibilização, em quantidade e qualidade, de modo lento e gradual (MELO \& MOTTA, 2011).

A diversidade de fauna e flora, também é um serviço ambiental importante, sendo que a manutenção desta é essencial para permitir o fluxo gênico e consequente reprodução das espécies, sejam elas macro ou microrganismos, os quais podem ser utilizados como fonte de alimentos, madeiras, combustível, fibras ou produtos medicinais; sendo responsáveis também pela renovação de nutrientes no solo e equilíbrio dinâmico dos ecossistemas (ALTEMBURG et al., 2010; ROQUE et al., 2010). Mediante os processos de fotossíntese e transpiração, a diversidade da flora contribui para a regulação climática equilibrando a composição atmosférica, devido à captação do dióxido de carbono e posterior armazenamento na biomassa vegetal, ou por sua contribuição incalculável na umidade relativa do ar, favorecendo as condições climáticas para sobrevivência dos seres (MYERS,1995; MARTINS et al., 2010)

Outro serviço ambiental prestado pelos ecossistemas é o equilíbrio de patógenos e de animais sinantrópicos, que podem ocasionar doenças nos seres humanos. Em diversos momentos históricos a ação antrópica resultou em desequilíbrio dos processos ecológicos, afetando diretamente a saúde pública (TAUIL, 2006). Doenças como a malária (CAMARGO, 2003), leishmaniose (DRUMOND \& COSTA, 2011), esquistossomose (KATZ \& PEIXOTO, 2000), leptospirose (BARCELLOS et al., 2003) são algumas das doenças em que houve o aumento dos vetores devido à desmatamentos, perda de habitat, poluição, principalmente de corpos d'água. Desta forma, a conservação dos ecossistemas faz-se necessária também para o estado de saúde dos seres humanos e manutenção de qualidade de vida.

Os serviços ambientais podem ser agrupados segundo sua função (TEEB, 2010), podendo ser classificados em: serviços de provisão (água, alimentos, madeiras, fibras e óleos vegetais, fitoterápicos etc.); serviços de suporte (ciclagem de nutrientes no solo, polinização e dispersão de sementes, controle biológico de pragas e doenças); serviços de regulação (ciclo das águas e regulação do regime de chuvas, estruturação dos solos com diminuição dos impactos de erosão e estabilização de encostas); serviços culturais e de lazer.

Contudo, para que esses serviços ambientais sejam disponibilizados pelos ecossistemas em quantidade e qualidade é necessário fundamentalmente que o solo esteja vivo e funcional, e em condições adequadas para o crescimento e desenvolvimento de macro e microrganismos e que os fatores abióticos estejam em um equilíbrio dinâmico. 
Quadro 1: Características dos sistemas de agricultura industrial, modelo revolução verde, e agroecologia quanto aos impactos nos recursos naturais e serviços ambientais.

\begin{tabular}{|c|c|c|}
\hline & AGRICULTURA INDUSTRIAL (REVOLUÇÃO VERDE) & AGROECOLOGIA \\
\hline $\begin{array}{l}\text { SOLOS - } \\
\text { BIOESTRUTURA }\end{array}$ & $\begin{array}{l}\text { Uso intensivo de máquinas pesadas; o uso sistemático e } \\
\text { repetitivo do arado e grade agrícola quebra a estrutura do solo, } \\
\text { tornando-o vulnerável a erosão. A ausência de cobertura vegetal } \\
\text { traz enormes danos às condições de vida no solo. }\end{array}$ & \multirow{3}{*}{$\begin{array}{l}\text { Pela visão sistêmica da agroecologia é possível reunir as } \\
\text { características relativas ao solo. Processos como } \\
\text { adubação verde e/ou orgânica proporcionam um aumento } \\
\text { de massa verde, matéria orgânica e cobertura morta que } \\
\text { ativam os microorganismos de solos e alimentam toda } \\
\text { uma gama de outros seres vivos presentes na terra. O } \\
\text { solo vivo permanece estruturado e permite a infiltração da } \\
\text { água que abastece os lençóis freáticos, diminui o } \\
\text { escoamento superficial reduzindo processos de erosão e } \\
\text { deposição de sedimentos nos corpos d'água. Não se } \\
\text { utiliza de agroquímicos, assim não poluem e nem } \\
\text { contaminam solos, lençóis freáticos ou cursos d'água. O } \\
\text { modelo agroecológico pode ser entendido como sistema } \\
\text { produtor de água. }\end{array}$} \\
\hline $\begin{array}{l}\text { SOLOS - } \\
\text { MICROBIOLOGIA }\end{array}$ & $\begin{array}{l}\text { Além dos processos de aração e gradagem, a exposição da } \\
\text { camada superficial ao sol e o uso intensivo de adubos químicos } \\
\text { e pesticidas salinizam os solos e prejudicam as condições de } \\
\text { vida e sua dinâmica. }\end{array}$ & \\
\hline SOLOS - RIOS & $\begin{array}{l}\text { Como os processos de erosão são bem mais intensos pelas } \\
\text { características acima, as águas dos rios acabam por receber } \\
\text { não só sedimentos de solo, que provocam seu assoreamento, } \\
\text { mas também uma contínua carga de fertilizantes e venenos } \\
\text { agrícolas. Os fertilizantes induzem a um super crescimento de } \\
\text { algas e outros vegetais, causando desequilibrio nos } \\
\text { ecossistemas, que podem acabar por gerar um processo de } \\
\text { eutrofização dos corpos d'água. Transportam também os } \\
\text { venenos agrícolas, que além de causarem efeitos como o } \\
\text { próprio nome já sugere, têm sido detectados atuarem como } \\
\text { disruptores endócrinos, causando, entre outros efeitos, } \\
\text { mudanças na expressão sexual de peixes e anfíbios (para uma } \\
\text { revisão sobre estas moléculas veja Santamarta } 2001 \text {, ou pelo } \\
\text { site www.nossofuturoroubado.com.br). }\end{array}$ & \\
\hline $\begin{array}{l}\text { AGUA - SOLOS - } \\
\text { LENÇOL } \\
\text { FREẢTICO }\end{array}$ & $\begin{array}{l}\text { A falta de estruturação dos solos neste modelo provoca uma } \\
\text { diminuição da infiltração das águas e um aumento do } \\
\text { escoamento superficial, fato que, invariavelmente provoca } \\
\text { rebaixamento do lençol freático. }\end{array}$ & $\begin{array}{l}\text { Os solos bem estruturados e com cobertura permitem a } \\
\text { infiltração da água promovendo a reposição das águas } \\
\text { subterrâneas }\end{array}$ \\
\hline ÁGUA - RIOS & $\begin{array}{l}\text { O solo desestruturado e sem cobertura faz com que se tenha } \\
\text { um maior escoamento superficial das águas das chuvas, que } \\
\text { correm rapidamente para os leitos dos rios, estes muitas vezes } \\
\text { desprovidos de mata ciliar, e com o grande aporte repentino de } \\
\text { águas que não infiltram no solo, tornam as enchentes dos rios } \\
\text { mais frequentes, causando grandes problemas de inundações } \\
\text { com enormes prejuízos às populações ribeirinhas. }\end{array}$ & $\begin{array}{l}\text { Como o processo de infiltração de água no solo ocorre } \\
\text { naturalmente, o escoamento superficial é minimizado } \\
\text { durante as chuvas, as águas chegam aos rios lentamente } \\
\text { fazendo com as cheias sejam menos intensas e não tão } \\
\text { súbitas. }\end{array}$ \\
\hline BIODIVERSIDADE & $\begin{array}{l}\text { O uso intensivo de agrotóxicos tem conseqüência direta na } \\
\text { biodiversidade, pois ataca não somente "as pragas", mas } \\
\text { também toda sorte de inimigos naturais, polinizadores, aves, } \\
\text { podendo atingir toda a cadeia trófica. }\end{array}$ & $\begin{array}{l}\text { Os cultivos diversificados e o uso de plantas nativas } \\
\text { adaptadas ao local provêm habitats para toda a fauna. } \\
\text { Insetos que auxiliam o equilíbrio de "pragas agrícolas" } \\
\text { (controle biológico) e polinizadores não são afetados. }\end{array}$ \\
\hline $\begin{array}{l}\text { ALIMENTOS - } \\
\text { QUALIDADE }\end{array}$ & $\begin{array}{l}\text { Produz alimentos com excessos agrotóxicos (veja relatório } \\
\text { ANVISA: Programa de Análise de Resíduos de Agrotóxicos em } \\
\text { Alimentos (PARA) - link para acesso: } \\
\text { http://portal.anvisa.gov.br/wps/wcm/connect/b380fe004965d38a } \\
\text { b6abf74ed75891ae/Relat\%C3\%B3rio+PARA+2010+- } \\
\text { +Vers\%C3\%A3o+Final.pdf?MOD=AJPERES }\end{array}$ & $\begin{array}{l}\text { A agroecologia produz alimento que não apresentam } \\
\text { qualquer resíduo de venenos agrícolas. }\end{array}$ \\
\hline $\begin{array}{l}\text { QUESTÕES } \\
\text { SOCIO-CULTURAIS }\end{array}$ & $\begin{array}{l}\text { Trabalhadores rurais sofrem frequentemente doenças causadas } \\
\text { pela exposição aos agrotóxicos, não sendo raros os casos de } \\
\text { morte, incluindo suicídios (MENEGHEL et al. 2004) } \\
\text { Normalmente sofrem exploração e infelizmente ainda é comum } \\
\text { encontrar trabalhadores rurais em condições de escravidão. } \\
\text { Este modelo induz ao êxodo rural e ao inchaço das grandes } \\
\text { cidades. }\end{array}$ & $\begin{array}{l}\text { O modelo agroecológico é orientado pela autonomia e } \\
\text { soberania dos povos, buscando a auto-suficiencia e a } \\
\text { valorização do trabalhador rural }\end{array}$ \\
\hline SEMENTES & $\begin{array}{l}\text { Cria dependência das empresas de sementes e de tecnologias. } \\
\text { As sementes produzidas pelas grandes indústrias são } \\
\text { desenvolvidas para uso com adubos químicos e agrotóxicos, ou } \\
\text { seja, não produzem sem o grande aporte de insumos externos. }\end{array}$ & $\begin{array}{l}\text { As sementes podem ser produzidas pelo próprio } \\
\text { agricultor. Sendo desenvolvida geneticamente às } \\
\text { condições de clima e solo local. }\end{array}$ \\
\hline $\begin{array}{l}\text { EMPREGO E } \\
\text { RENDA }\end{array}$ & $\begin{array}{l}\text { A intensa mecanização torna este modelo bastante pobre na } \\
\text { geração de emprego, ocasionando êxodo rural. }\end{array}$ & $\begin{array}{l}\text { Cultivos diversificados com o mínimo de insumos externos } \\
\text { necessitam de maior volume de trabalho, utilizam mais } \\
\text { mão de obra e geram mais empregos. A partir da } \\
\text { valorização do trabalho do homem no campo é possível } \\
\text { fixar boa parte da humanidade nos campos, promovendo } \\
\text { uma diminuição no contingente humano que vivem sob } \\
\text { precárias condições em aglomerados nos grandes centros } \\
\text { urbanos. }\end{array}$ \\
\hline
\end{tabular}

\section{Solos Vivos}

"Modificando somente um único fator do complexo ecológico (o solo), modificam-se todos os demais fatores automaticamente, a fim de formar um equilíbrio novo em que cabe o fator modificado." (PRIMAVESI, 1988, p.7). O solo é um capital natural, um recurso básico que suporta a cobertura vegetal do planeta permitindo a existência de todos os seres vivos (BERTONI \& LOMBARDI NETO, 1990). Sua estrutura, ou bioestrutura, é devida a existência de grumos estáveis à água, e que dependem de agentes coloidais ou 'cola orgânica' produzida por uma série 
de microrganismos, e é portanto um equilíbrio dinâmico, dependendo de renovação periódica e constante (PRIMAVESI, 1988). Os grumos são também responsáveis pela grande presença de macro e microporos essenciais a circulação de ar e infiltração de água, fundamentais para o funcionamento saudável do solo em sua capacidade de infiltração e retenção de água (PRIMAVESI, 1988; GONÇALVES et al., 2008).

A agricultura industrial ou moderna (modelo 'revolução verde') é a forma de uso do solo que demonstra alto potencial de interferência, devido à utilização intensa de pesadas máquinas agrícolas que compactam e desestruturam o solo, que associada ao uso constante de fertilizante químicos, típicos da monocultura, provoca salinização e drástica redução na vida e na quantidade de matéria orgânica presentes nos solos. Estes processos favorecem a erosão e assoreamento dos corpos d'água, entre outros danos (LUTZENBERGER, 2001; PERIN et al., 2003; CAPORAL et al., 2006; GONÇALVES et al., 2008; PELLEGRINI et al., 2008; ALTIERI, 2009). Estas consequências implicam na perda de alguns serviços ambientais como diversidade de micro e macrorganismos nos solos, alterações no processo de infiltração de água, modificando qualidade e quantidade dos lençóis freáticos; equilíbrio nutricional do solo - acarretando no empobrecimento e salinização (Tabela 1). Deve-se considerar ainda que na grande maioria das vezes os processos de erosão e escoamento superficial transportam adubos químicos e/ou venenos agrícolas para cursos e corpos d'água. Relatório da FAO (Organização das Nações Unidas para Agricultura e Alimentação), publicado em novembro de 2011 , aponta que $25 \%$ dos solos do planeta estão degradados, o que certamente afetará a produção mundial de alimentos.

\section{Valoração e Economia Ecológica}

A valoração ambiental pode ser considerada um importante instrumento econômico para a conservação dos recursos naturais (ORTIZ, 2003; ROMEIRO \& MAIA, 2004), visto que contabiliza os serviços ambientais. Contudo, sua importância maior está no fato de nos chamar atenção para externalidades sobre os serviços ambientais, antes negadas pela economia neoclássica. Apresenta também grande potencial para sensibilizar a sociedade para mudanças de paradigmas na base produtiva e no consumismo (TEEB, 2010). Segundo ainda Romeiro e Maia (2004) a valoração deve ser associada a instrumentos de comando e controle baseadas em parâmetros de sustentabilidade para obter os resultados esperados. A ausência de bons indicadores de sustentabilidade, nos quais se possam abarcar as várias dimensões, é um grande desafio a ser superado (GUIMARÃES \& FEICHAS, 2009; VEIGA, 2010).

Segundo TEEB (2010), a valoração dos recursos biológicos pode interferir diretamente nas tomadas de decisões da gestão pública, que determina a conservação ou degradação destes recursos. E se as políticas públicas incorporam programas de educação ambiental, sensibilizando a sociedade para estas questões, é bem possível que haja uma mudança de comportamento em 
toda a sociedade, que passará a exigir adequações dos setores produtivos e comerciais para que estudem os riscos e minimizem as externalidades indesejadas.

O pagamento por serviços ambientais (PSA) tem por objetivo proteger os recursos naturais e os benefícios providos pelos ecossistemas (FOREST TRENDS, 2008). O PSA visa compensar o indivíduo que adote práticas conservacionistas, para a manutenção dos serviços ambientais em sua extensão territorial, a partir do aporte monetário, por meio de contratos diretos e/ou subordinados a programas governamentais, e desta forma reduzir as emissões para o desmatamento e degradação (REDD), e conservar e manter o ambiente natural (LERDA \& ZWICK, 2010; WUNDER, 2005).

O PSA também apresenta benefícios sociais, como movimentação da economia local e pelo envolvimento dos cidadãos e seus representantes nas discussões ambientais (VEIGA NETO, 2008). Programas de transferência de renda, como a 'Bolsa Floresta' também podem ser considerados como outras formas de PSA, os quais podem e devem estar atrelados a programas de desenvolvimento local e promoção da saúde comunitária (VIANA, 2008).

Em geral, os projetos de pagamentos por serviços ambientais desenvolvidos na Mata Atlântica utilizam os métodos de custo de reposição e oportunidade, e variam de acordo com o contexto local, seja ele Estado ou Município. Tais métodos são ferramentas utilizadas de acordo com valores de uso direto e indireto, e são ajustados para cada projeto. O que depende de quais serviços ambientais serão disponibilizados pelos ecossistemas inseridos na propriedade rural (GUEDES \& SEEHUSEN, 2011). Os aspectos da valoração e os programas e projetos para pagamento por serviços ambientais devem ser claros, para facilitar a adesão dos atores locais. Assim, algumas definições importantes são: quais são os serviços promovidos; quem é o comprador e quem é o fornecedor; qual a motivação e disposição a pagar; de onde vem o recurso financeiro utilizado e se a forma de adquiri-lo se dá de forma contínua ou pontual (VEIGA NETO, 2008).

Outros fatores que podem influenciar na aplicação do PSA são a inexistência ou deficiência de informações sobre a necessidade e contribuição do pagamento, tanto para os fornecedores quanto para os compradores de serviços ambientais. A escassez de fontes financeiras, a falta de metodologias que possa incluir todas as dimensões necessárias para o cálculo dos pagamentos, legislação pertinente ainda bastante incipiente e a baixa quantidade de compradores são obstáculos a serem vencidos (FOREST TRENDS, 2008). Cavalcanti (2010) nos alerta sobre o perigo de se atribuir valor monetário aos recursos naturais e aos serviços ambientais, pela possibilidade de se considerar que eles possam valer o preço atribuído, podendo ser incorporado a ativos financeiros, e pensados serem substituíveis. Para Veiga (2010) sempre será um exercício arbitrário atribuir grandezas monetárias a prejuízos ou ganhos que não têm preços determinados por mercados.

Cavalcanti (2010) considera ainda que a sustentabilidade ecológica deve ser entendida como "manutenção de estoques físicos de capital natural, não a de seus correspondentes valores 
monetários" (p.63) pensamento considerado como 'sustentabilidade forte', segundo pensamentos da economia ecológica, apontando a necessidade de desenvolvermos uma visão ecológica da economia. Ainda segundo Cavalcanti (2010), a economia ecológica surgiu exatamente da reflexão sobre a percepção que o sistema ecológico de sustentação da vida encontra-se cada vez mais ameaçado. Para Caporal e colaboradores (2006), na visão da economia neoclássica e da economia ambiental, a ecologia é considerada um objeto da economia, mas na economia ecológica é a economia que está subordinada a ecologia.

\section{Agroecologia e Agroflorestas}

Nos dias de hoje, constatado os danos aos recursos naturais e também na qualidade dos alimentos, a agroecologia surge como potencial estratégia agrícola capaz de conciliar a produção agropecuária e conservação dos recursos naturais (WORSTER, 2003; ALTIERI, 2009). A agroecologia procura estabelecer alternativas que minimizem a artificializarão do ambiente natural, tendo como premissas básicas o bom uso dos solos e dos recursos hídricos.

Na natureza, a estabilidade está ligada à diversidade, sendo a agricultura, como é pensada hoje, uma atividade que rompe o equilíbrio natural e a resiliência dos agro ecossistemas, ao estabelecer uma simplificação do ecossistema original (ASSIS, 2006). Caporal et al. (2006, p.3) sintetizam como "manejo ecologicamente responsável dos recursos naturais, que parte de um enfoque holístico e de uma abordagem sistêmica, que pretende contribuir para que possamos redirecionar o curso alterado de co-evolução social e ecológica".

Além das questões técnicas relativas à produção, a agroecologia traz para a discussão a importância de se introduzir os aspectos socioeconômicos, resgatando o valor do processo sociocultural da agricultura (ASSIS, 2006). Segundo Caporal e colaboradores (2006), a agroecologia se apresenta como uma matriz disciplinar integradora, totalizante, holística, capaz de aprender e aplicar conhecimentos gerados em diferentes disciplinas. Carmo (2008) considera importante também a característica da agroecologia em não aceitar o modelo de crescimento voltado exclusivamente ao mercado, e a coloca como potencializadora para uma transição que desenvolva laços de solidariedade entre os povos.

O sistema agroflorestal é uma forma de uso do solo que é capaz de conciliar produção agrícola com conservação dos recursos naturais (JOSE, 2009; LUNELLI et al. 2013), produzindo serviços ambientais como: proteção dos solos (ALAVALAPATI et al., 2004), minimizando eventos de erosão (SANTOS \& PAIVA, 2002; GARCIA-BARRIUS \& ONG, 2004), melhorando a ciclagem de nutrientes (KUMAR \& NAIR, 2004; MAIA et al., 2006), a fertilidade e estrutura física (GARCIABARRIUS \& ONG, 2004; CARVALHO et al., 2004); melhorias no ciclo da água, aumentando a capacidade de retenção (GARCIA-BARRIUS \& ONG, 2004) e também em sua qualidade (ALAVALAPATI et al., 2004); podem prover habitats para fauna (BHAGWAT et al., 2008) com ganhos na conservação da biodiversidade por permitir maior conectividade entre fragmentos, 
reduzindo também a pressão sobre as áreas protegidas (BHAGWAT et al., 2008); diminuição dos gases de efeito estufa através do sequestro de carbono (ALAVALAPATI et al., 2004); além de benefícios em aspectos socioeconômicos, voltados principalmente para agricultura familiar (KUMAR \& NAIR, 2004; RAMOS et al., 2009; VICENTE et al., 2011; OLIVEIRA JÚNIOR \& CABREIRA, 2012). Dentre os principais ganhos dos SAFs nas questões socioeconômicas são destacados por Kumar e Nair (2004): aumento da autossuficiência, aumento da segurança alimentar e melhores condições para preservação dos conhecimentos tradicionais relativos aos recursos biológicos.

\section{CONCLUSÕES}

O Brasil possui ecossistemas importantes para a manutenção da vida e dos seres vivos, e até o planeta. Por isso deve desenvolver instrumentos políticos e econômicos a fim de preservar os ecossistemas e os serviços ambientais. No entanto, esta mudança será mais efetiva se for uma mudança na forma como nos relacionamos com a terra, sem que se tenha a necessidade de se utilizar compensações financeiras ou de multas para tal. A agricultura é um forte agente de transformação da crosta terrestre. A comparação entre os modelos de agricultura industrial (derivado da revolução verde) e da agroecologia (Tabela 1) nos mostra que o modelo industrial apresenta basicamente externalidades negativas (destruição dos solos, contaminação e assoreamentos dos cursos e corpos d'água, degradação e contaminação da biodiversidade, entre outros efeitos) e a agroecologia, de modo contrário, produz externalidades positivas, preservando os serviços ambientais, essenciais para manutenção de condições de vida no planeta, como preconiza a economia ecologia, ela preserva a base produtiva, formada pelos recursos naturais, como solos, água, florestas e biodiversidade. Pode-se até pensar que o modelo industrial é mais produtivo, se pensarmos exclusivamente na produtividade agrícola, dentro do pensamento da economia neoclássica, mas quando avaliamos as externalidades promovidas pelos dois sistemas, e se fosse possível embutirmos todos os valores monetários da destruição causada pelo modelo industrial aos serviços ambientais, o modelo agroecológico seria mais vantajoso até sob olhar da economia neoclássica.

Num primeiro momento pode-se até argumentar que a agricultura de base ecológica não conseguirá produzir alimentos para toda humanidade. De fato, a produtividade agrícola do modelo industrial parece ser maior que o modelo agroecológico, isto é, sem considerarmos as externalidades consequentes de cada modelo e sem considerarmos também sua eficiência energética. No entanto, a "menor produtividade" da agroecologia poderia facilmente ser contornada pelo aumento da área plantada, a partir de uma maior eficiência no planejamento do uso do solo, preferencialmente, pensadas, por bacias hidrográficas e utilizando instrumentos como o zoneamento econômico-ecológico, corrigindo-se deste modo, velhos problemas brasileiros, 
como a grande quantidade de terras improdutivas e sua má distribuição (MARTINELLI et al., 2010).

Para que projetos de PSA alcancem os resultados esperados é necessário um bom planejamento e o reconhecimento das características da bacia hidrográfica local, das condições socioeconômicas e culturais. É fundamental o levantamento da quase totalidade dos ganhos e perdas, reduzindo as chances de fracasso. Valorizar os produtores rurais, principalmente a agricultura familiar e priorizar a produção de alimentos saudáveis é condição sine qua non para o desenvolvimento rural sustentável, assim como considerar os ciclos biogeoquímicos e de energia que regem os processos ecológicos. Para a TEEB (2010) valorar os serviços ecossistêmicos em termos monetários pode ser complexo e controverso. Pensar os PSA utilizando a mesma lógica da economia neoclássica ou mesmo da economia ambiental, analisados, planejados e valorados com base em indicadores limitados e obsoletos como o PIB (produto interno bruto) e mesmo o IDH (índice de desenvolvimento humano), com certeza não conseguiremos desenvolver um olhar sistêmico que possa traçar estratégias para permitir o alcance do equilíbrio e resiliência dos ecossistemas, e como consequência, prover condições para a continuidade dos ciclos biogeoquímicos e dos serviços ambientais. Embora se possa pensar em tecnologias 'ganha-ganha' (ROMEIRO, 2011), remunerando as externalidades positivas produzidas pelos agricultores, seria muito mais interessante incentivos que visassem transformação e transição para o paradigma agroecológico, incorporando consciência e desejo de se ter uma natureza equilibrada.

\section{REFERÊNCIAS}

ALAVALAPATI, J. R .R.; SHRESTHA, R. K.; STAINBACK, G. A.; MATTA, J. R.. Agroforestry development: an environmental economic perspective. Agroforestry Systems, v.61, p.299-310, 2004.

ALTEMBURG, S. N.; LUZZARDI, R.; LOVATTO, P. B.. O importante papel da biodiversidade biológica na qualidade do solo em sistemas de produção agrícola: um enfoque para microbiologia edáfica como bioindicadora. Caderno de Pesquisa série Biologia, v.22, n.2, p.18-36, 2010.

ALTIERI, M.. Agroecologia: a dinâmica produtiva da agricultura sustentável. 5 ed. Porto Alegre: Editora da UFRGS, 2009.

ASSIS, R. L.. Desenvolvimento rural sustentável no Brasil: perspectivas a partir da integração de ações públicas e privadas com base na agroecologia. Economia Aplicada, v.10, n.1, p.75-89, 2006.

BALSAN, R. Impactos decorrentes da modernização da agricultura brasileira. Campo-Território: revista de geografia agrária, v.1, n.2, p.123-151, 2006.

BARCELLOS, C.; LAMMERHIRT, C. B.; ALMEIDA, M. A. B.; SANTOS, E. Distribuição espacial da leptospirose no Rio Grande do Sul, Brasil: recuperando a ecologia dos estudos ecológicos. Caderno de Saúde Pública, Rio de Janeiro, v.19, n.5, p.1283-1292, 2003.

BERTONI, J.; LOMBARDI NETO, F.. Conservação do solo. São Paulo: Ícone, 1990.

BHAGWAT, S. A.; WILLIS, K.J.; BIRKS, J.B.; WHITTAKER, R. J.. Agroforestry: a refuge for tropical biodiversity?. Trends in Ecology and Evolution, v.23, n.5, p.261-267, 2008.

BROOKS, T. M.; MITTERMEIER, R.A.; FONSECA, G.A.B.; GERLACH, J.; HOFFMANN, M.; LAMOREUX, J.F.; MITTERMEIER, C. G.; PILGRIM, J. D.; RODRIGUES, A. S. L.. Global biodiversity conservation priorities. Science, v.313, n.7, p.58-6, 2006. 
CAMARO, E. P. Malária, maleita, paludismo. Ciência e Cultura, v.55, n.1, p.26-29, 2003.

CAPORAL, F. R.; COSTABEBER, J. A.; PAULUS, G.. Agroecologia: matriz disciplinar ou novo paradigma para o desenvolvimento rural. Brasília: MDA, 2006.

CARMO, M. S.. Agroecologia: novos caminhos para a agricultura familiar. Revista Tecnologia \& Inovação Agropecuária, p.28-40, 2008.

CARVALHO, R.; GOEDERT, W. J.; ARMANDO, M. S.. Atributos físicos da qualidade de um solo sob sistema agroflorestal. Pesquisa Agropecuária Brasileira, v.39, n.11, p.1153-1155, 2004.

CAVALCANTI, C.. Concepções da economia ecológica: suas relações com a economia dominante e a economia ambiental. Estudos Avançados, v.24, n.68, p.53-67, 2010.

DAL-SOGLIO, F.; KUBO, R. R.. Agricultura e sustentabilidade. Porto Alegre: UFRGS, 2009.

DAL-SOGLIO, F.. A crise ambiental planetária, a agricultura e o desenvolvimento. In: DAL-SOGLIO, F.; KUBO, R. R.. Agricultura e sustentabilidade. Porto Alegre: UFRGS, p.13-32, 2009.

DRUMOND, K. O.; COSTA, F. A. L.. Forty years of visceral leishmaniasis in the state of Piauí: a review. Revista Instituto Medicina Tropical, v.53, n.1, p.3-11, 2011.

EHLERS, E.. Agricultura sustentável: origens e perspectivas de um novo paradigma. São Paulo: Livros da Terra, 1996.

FASIABEN, M. C. R.; ANDRADE, D. C.; REYDON, B.P.; GARCIA, J. R.; ROMEIRO, A. R.. Estimativa de aporte de recursos para um sistema de Pagamento por Serviços Ambientais na floresta Amazônica brasileira. Ambiente \& Sociedade, v.7, n.2, p.223-239, 2009.

FOREST, T.; KATOOMBA, G.; PNUMA.. Pagamentos por Serviços Ambientais: um manual sobre como iniciar. São Paulo: 2008.

GARCIA-BARRIUS, L.; ONG, C. K. Ecological interactions, management lessons and design tools in tropical agroforestry systems. Agroforestry Systems, v.61, p.221-236, 2004.

GONÇALVES, J. L. M.; NOGUEIRA JR, L. R.; DUCATTI, F.. Recuperação de solos degradados. In: KAGEYAMA, P. Y.. Restauração ecológica de ecossistemas naturais. Botucatu: FEPAF, p.111-163, 2008.

GÖTSCH, E.. Homem e natureza: cultura na agricultura. 2 ed. Recife: Centro Sabiá, 1997.

GUEDES, F. B.; SEEHUSEN, S. E.. Pagamento por Serviços Ambientais na Mata Atlântica: lições aprendidas e desafios. Brasilia: MMA, 2011.

GUIMARÃES, R. P.; FEICHAS, S. A. Q.. Desafios na construção de indicadores de sustentabilidade. Ambiente e Sociedade, v.7, n.2, p.307-323, 2009.

JOSE, S.. Agroforestry for ecosystem services and environmental benefits: an overview. Agroforestry Systems, v.76, p.1-10, 2009.

KATZ, N.; PEIXOTO, S. V.. Análise crítica da estimativa do número de portadores de esquistossomose mansoni no Brasil. Revista da Sociedade Brasileira de Medicina Tropical, v.33, n.3, p.303-308, 2000.

KUMAR, B. M.; NAIR, P. K. R.. The enigma of tropical homegardens. Agroforestry Systems, v.61, p.135152, 2004.

LERDA, D.; ZWICK, S.. Um breve panorama dos pagamentos por serviços ambientais no Brasil. Brasília: FUNBIO, 2010.

LUNELLI, N. P.; RAMOS, S. F.; OLIVERA JUNIOR, C. J. F.. Agroflorestas e externalidades. Revista Verde de Agroecologia e Desenvolvimento Sustentável, v.8, n.5, p.163-170, 2013.

LUTZENBERGER, J. A.. O absurdo da agricultura. Estudos Avançados, v.15, n.43, p.61-74, 2001. 
MA - MILLENNIUM ECOSYSTEM ASSESSMENT. Millennium ecosystem assessment: general synthesis report. Washington DC: Island Press, 2005.

MAIA, S. M. F.; XAVIER, F. A. S.; OLIVEIRA, T. S.; MENDONÇA, E. S.; ARAUJO FILHO, J. A.. Impactos de Sistemas Agroflorestais e Convencional sobre a qualidade do solo no semi-árido Cearense. Revista Árvore, v.30, n.5, p.837-848, 2006.

MARTINELLI, L. A.; JOLY, C. A.; NOBRE, C. A.; SPAROVEK, G.. A falsa dicotomia entre a preservação da vegetação natural e a produção agropecuária. Biota Neotropica, v.10, n.4, 2010.

MENEGHEL, S. N.; VICTORA, C. G.; FARIA, N. M. X.; CARVALHO, L. A.; FALK, J. W.. Características epidemiológicas do suicídio no Rio Grande do Sul. Revista de Saúde Pública, v.38, n.6, p.804-810, 2004.

MORAN, E. F.. Nós e a natureza: uma introdução às relações homem-ambiente. São Paulo: Senac, 2008.

MORAN, E. F.; OSTROM, E.. Ecossistemas florestais: interação homem-ambiente. ALVES, D. S.; BATISTELLA, M.. (Trad.) São Paulo: Edusp, 2009.

MOTTA, R. S.. Valoração e precificação dos recursos ambientais para uma economia verde: Política Ambiental: Economia verde desafios e oportunidades. Revista Politica Ambiental. n.8, p.179-190, 2011.

MYERS, N.. Environmental services of biodiversity. Proceedings of the National Academy of Sciences. v. 93, p.2764-2769, 1996.

NASCIMENTO, H. M.. Pioneiros da ecologia política agrária contemporânea. Ambiente e Sociedade, v.12, n.2, p.257-272, 2009.

NOGUEIRA, J. M.; MEDEIROS, M. A. A.; ARRUDA, F. S. T.. Valoração Econômica do Meio Ambiente: Ciência ou Empiricismo?. Cadernos de Ciência \& Tecnologia, v.17, n.2, p.81-115, 2000.

OLIVEIRA JÚNIOR, C. J. F.; CABREIRA, P. P.. Sistemas agroflorestais: potencial econômico da biodiversidade vegetal a partir do conhecimento radicional ou local. Revista Verde de Agroecologia e Desenvolvimento Sustentável, v.7, n.1, p.212-224, 2012.

PACÍFICO, D. A.. História da modernização da agricultura: um conto de muitas facetas. Porto Alegre, UFRGS, p.33-45, 2009.

PELLEGRINI, J. B. R.; SANTOS, D. R.; GONÇALVES, C. S.; COPETTI, A. C. C.; BORTOLUZZI, E. C.. Adsorção de fósforo em sedimentos e sua relação com a ação antrópica. Revista Brasileira de Ciências do Solo, v.32, p.2639-2646, 2008.

PERIN, E.; CERETTA, C. A.; KLAMT, E.. Tempo de uso agrícola e propriedades químicas de dois latossolos do Planalto Médio do Rio Grande do Sul. Revista Brasileira de Ciências do Solo, v.27, p.665-674, 2003.

PRIMAVESI, A.. Manejo ecológico do solo: a agricultura em regiões tropicais. 9 ed. São Paulo: Nobel, 1988.

RAMOS, S. F.; CHABARIBERY, D.; MONTEIRO, A. V. V. M.; SILVA, J. R.. Sistemas agroflorestais: estratégia para a preservação ambiental e geração de renda aos agricultores familiares. Informações Econômicas, v. 39, n.6, p.37-48, 2009.

ROMEIRO, A. R.. Política Ambiental: Economia Verde, Desafios e Oportunidades, Revista Gema, Rio de Janerio, n.8, p.123-130, 2011.

ROMEIRO, A. R.; MAIA, A. G.. Programa avaliação socioeconômica de projetos: avaliação de custos e benefícios ambientais. São Paulo: Escola Nacional de Administração Pública, 2004.

ROMEIRO, A. R.. Economia do meio ambiente: teoria e prática. Rio de Janeiro: Elsevier, 2003.

ROQUE, A. A.; ROCHA, R. M.; LOIOLA, M. I. B. Uso e diversidade de plantas medicinais da Caatinga na comunidade rural de Laginhas, município de Caicó, Rio Grande do Norte. Revista Brasileira de Plantas Medicinais, v.12, n.1, p.31-42, 2010. 
SACHS, I.. Barricadas de ontem, campos de futuro. Estudos Avançados, v. 24, n.68, p.25-38, 2010.

SANTAMARTA, J.. A ameaça dos disruptores endócrinos. Agroecologia e Desenvolvimento Rural Sustentável, v.2, n.3, p.18-29, 2001.

SANTOS, M. J. C.; PAIVA, S. N.. Os sistemas agroflorestais como alternativa econômica em pequenas propriedades rurais: estudo de caso. Ciência Florestal, v.12, n.1, p.135-141, 2002.

TAUIL, P. L.. Perspectivas de controle de doenças transmitidas por vetores no Brasil. Revista da Sociedade Brasileira de Medicina Tropical, v.39, n.3, p.275-277, 2006.

TEEB.A economia dos ecossistemas e da biodiversidade: integrando a economia da natureza. Uma síntese da abordagem, conclusões e recomendações do TEEB. São Paulo: 2010.

VEIGA, J. E.; EHLERS, E.. Economia do meio ambiente: teoria e prática. Rio de Janeiro: Elsevier, 2003. VEIGA NETO, F. C.. A construção dos mercados de serviços ambientais e suas implicações para o desenvolvimento sustentável no Brasil. Tese (Doutorado em Desenvolvimento, Agricultura e Sociedade) - Universidade Federal Rural do Rio de Janeiro, Rio de Janeiro, 2008.

VEIGA, J. E.. Indicadores de sustentabilidade. Estudos Avançados, v.24, n.68, p.39-52, 2010.

VIANA, V. M.. Bolsa floresta: um instrumento inovador para a promoção da saúde em comunidades tradicionais na Amazônia. Estudos Avançados, v.22, p.64, p.143-153, 2008.

WORSTER, D.. Transformações da Terra: para uma perspectiva agroecológica na história. Ambiente \& Sociedade, v.6, n.1, p.23-44, 2003. 